Purdue University

Purdue e-Pubs

Charleston Library Conference

\title{
Using a Community of Practice Approach to Transform: How an Academic Library Collections Unit Reorganized to Meet Growing Demands for E-Resources and Services During a Time of Institutional Change
}

John Abresch

University of South Florida, jabresch@usf.edu

Follow this and additional works at: https://docs.lib.purdue.edu/charleston

Part of the Collection Development and Management Commons

An indexed, print copy of the Proceedings is also available for purchase at:

http://www.thepress.purdue.edu/series/charleston.

You may also be interested in the new series, Charleston Insights in Library, Archival, and Information Sciences. Find out more at: http://www.thepress.purdue.edu/series/charleston-insights-library-archivaland-information-sciences.

John Abresch, "Using a Community of Practice Approach to Transform: How an Academic Library Collections Unit Reorganized to Meet Growing Demands for E-Resources and Services During a Time of Institutional Change" (2018). Proceedings of the Charleston Library Conference.

http://dx.doi.org/https://doi.org/10.5703/1288284317029

This document has been made available through Purdue e-Pubs, a service of the Purdue University Libraries. Please contact epubs@purdue.edu for additional information. 


\title{
Using a Community of Practice Approach to Transform: How an Academic Library Collections Unit Reorganized to Meet Growing Demands for E-Resources and Services During a Time of Institutional Change
}

\author{
John Abresch, University of South Florida, jabresch@usf.edu
}

\begin{abstract}
In recent years, technical services operations and collection management at the University of South Florida (USF) Library was operating with flat budgets, a staff organization in a state of transition, ineffective workplace communication, and a progressive loss of institutional knowledge and skill sets. During the same time, the university was characterized by a fast-developing dynamic research and learning environment. New research endeavors and academic programs were incorporating a variety of electronic resources in their activities. In response, library administrators implemented a strategy of organizing technical services operations into a community of practice with three key elements. The three elements included redefining technical staff organization, enhancing collaboration and communication, and building new work areas. This paper illustrates how the technical services operations at USF was remodeled by modifying staff organization and workspaces into collaborative teams. The team approach has focused skill sets on multiformat collection problem solving and enhanced service delivery to library patrons. The reorganization has transformed a department previously centered on processing print publications to a department focused on managing diverse activities including evidence-based acquisitions programs in both e-book and streaming formats as well as diverse e-journal and database subscriptions. The new Collections \& Discovery Unit has a shared mission and vision. The unit staff members have built a knowledge base of diverse information and solutions to meet the challenges of a fast-changing academic landscape.
\end{abstract}

\section{Building a Library Technical Services Operation}

The University of South Florida, located in Tampa, Florida, is a comprehensive public research-level institution with an enrollment of over 50,000 students. Founded in 1956, the university has steadily developed from a regional school with a focus on undergraduate education to facilitating diverse graduate-level academic programs and research endeavors. A unique aspect of several of the academic programs at USF is an applied perspective. The applied perspective is evident in the myriad of laboratory settings, fieldwork opportunities, internships, and collaborations with other groups in the greater Tampa metropolitan area and beyond that students and faculty foster. An integral part of the learning and research environment at USF is the library. The library is a node not only providing the university community with information resources supporting instruction and research but also connecting students and faculty to a wider information network (University of South Florida System, 2017-2018).

From 1956 to the 1980s the library supported the university's mission in developing collections and information services to meet the university community's evolving needs. Opening in 1976, the collections were mostly print focused and housed in a 300,000-square-foot library building. Library administrators invested much of the library materials budget in maintaining serial subscriptions and in book approval plans. Following best practices and academic publishing trends, librarians at USF built extensive runs of scholarly journals with journal backfiles taking up large amounts of stacks space. Equally extensive were book holdings that extended across several floors of the library building. Other stacks spaces in the library housed government documents and microfilm collections.

Many of the titles in the library's book collection were purchased by the use of approval plans. An approval plan is a book order profile outlining subject areas that a library intends to purchase from a vendor. Collection management librarians arranged approval plan agreements with several vendors such as Yankee Book Peddler. Other books in the library collections were purchased as firm order requests to fulfill specific needs. Collection management librarians acquired journals and continuing resources through serial vendors or by direct subscription to publishers. Approval plans were a collection development tool of choice in that they provided an effective way in which 
to obtain a broad selection of current and scholarly books needed to support interdisciplinary curriculum and research activities at USF. Librarians managed all aspects of the book and serial life cycle, from administering approval plans and serial subscriptions to providing technical services leadership. Library staff provided support for many processing and functioning tasks needed to order, process, catalog, and make available materials for patrons.

With a large number of print publications to manage, library administrators had planned extensive workspaces to accommodate technical services processing of publications. Library administrators had placed technical services operations in the basement of the library building, which included both acquisitions and cataloging functions. Budget control and collection development decisions were associated with librarians and professional staff members located in other parts of the library building. The spaces for technical service processing were sizable, having the capacity to provide work areas for the physical handling of several hundred books and journals. Offices and workspaces for librarians and staff were dispersed along the basement floor. While the arrangement of the work areas was effective for production workflows associated with acquisitions and cataloging functions, the arrangement of the workspaces was not conducive to effective workplace communication. The processing of materials was steady but often experienced delays, in that some tasks related to daily workflows needed input from librarians or professional staff located elsewhere in the library. Despite the workflowrelated challenges, by 2010 the Technical Services Department was processing over 300 monographs a week. The staff was also processing over 4,000 print journal subscriptions. The year 2010 also marked a year of transition for the Technical Services Department, the organizational structure, the collection and service paradigm, and business models that had characterized collection management had begun a period of change.

\section{Adapting to a Changing Environment}

By 2010, the library began to experience the effects of several distinct trends at the university that affected its overall collection management practices. Library administrators had to deal with a convergence of trends including flat budgets, the changing landscape of scholarly publishing to more digital content, online courses, and evolving staff organization. The one factor that was constant during the period of institutional transitions was change itself. Library management recognized the need to build a flexible materials management model that was able to respond to diverse challenges but still build collections and offer access to diverse information resources to library patrons. The revamped collection management model would be multifaceted, integrating new spaces, technologies, operations, and organizational structure.

Responding to strategic directives emphasizing research and innovative instructional endeavors, the USF academic community by the mid-2000s had embraced electronic publications as integral components in research programs and new curriculum designs. University instructional policies mandated the use of distance learning technologies. Coursework was delivered to students in online learning modules such as Blackboard and Canvas in diverse academic disciplines. A key aspect of online learning modules is the use of digital publications, especially e-books and e-journals. Instructors would routinely add e-journal articles and e-book chapters to course assignments and reading lists. In order to meet the research and instructional demands of a changing university community, librarians sought to broaden the scope of scholarly publications accessible to students and faculty by investing in electronic resources and new acquisitions models. The print monograph and journal-focused technical services organization would have to evolve to meet a new focus on acquiring electronic content.

\section{Building E-Collections and Finding New Uses for Library Space}

After considering different strategies to offer electronic resources to the university community, collection librarians at USF decided to replace book approval plans with patron- and evidence-based acquisitions programs. The demand-driven acquisitions (DDA) model for e-books would offer a significant amount of vendor catalog e-book content for patrons. Several scholarly e-journal packages were also acquired that offered access to several thousand articles to faculty and students. The change in collection strategy was enabled by leveraging student technology fees in the form of grants to provide supplemental funding for the DDA program. The emphasis on building collections of e-books and e-journals not only enabled library administrators to diversify the library's collections with electronic content, it also provided an impetus to look at the use of space in the library building. 
One of the immediate effects of investing in journal backfiles and archives was the opportunity to weed print journals from the library collections. With perpetual access to several scholarly journals secured and with faculty approval, library administrators enacted collection weeding projects focused on print journals. The weeding exercises allowed the repurposing of an entire floor of the library building or about 50,000 square feet of space. Using a theme of student success, the floor redesign included quiet study spaces, collaborative spaces, study rooms, and instructional areas for undergraduate students. The redesigned floor was positively received by students and instructional faculty and used by many classes and student groups for meeting and study purposes. The success of the floor redesign prompted library administrators to examine how other space was used in the library such as for acquisitions and cataloging operations.

With a focus on processing electronic resources, the spaces needed by both acquisitions and cataloging for processing print materials were reduced. Library administrators sought to design spaces for technical services operations that encouraged more collaboration and communication. Library administrators also sought to lessen the communication and workflow issues that were affecting daily workflow procedures for processing collections, which were still optimized for print materials. Key decisions integral to the processing of materials in other formats, such as electronic resources, were not made in a timely manner due to a lack of staff members with relevant skills such as licensing and billing of electronic resources. The staffing situation was an effect of an organization experiencing several changes.

\section{Building a Community of Practice}

Coinciding with an increasing demand for electronic resources were significant changes in the composition of the individuals that were in technical services positions at the USF Library. In the early 2000s, the USF Library had approximately 30 full-time employees comprising both staff and librarian positions in the department. Librarians managed the professional aspects of workflow in both acquisitions and cataloging. Staff members performed a variety of daily fiscal, clerical, and physical processing tasks. The retirement of several key individuals in the department adversely affected decision making in several facets of processing collections including budget planning, licensing, and daily acquisitions workflow. The reduction in staff members continued and by early 2018 , the number of full-time staff members in the technical services area was around 15 full-time employees performing various functions.

In alleviating the situation, library administrators developed a plan to co-locate both acquisitions and cataloging staff to the sixth floor of the library building. The basement floor, which facilitated technical services processing, was converted to compact shelving and provided additional shelving space for a number of collections. In designing new technical services work areas, library administrators had also restructured the technical service employee organization to better facilitate collaborative interactions and decentralize decision-making for daily workflows. The new organization would borrow elements from communities of practice. A reorganized technical services unit would be a community of staff members sharing the same goals and vision. They would also possess the good communication skills required to build relationships and to work in a team environment (Wenger, 1998).

\section{Sustainable Library Technical Services}

The new library unit was branded the Collections and Discovery (C \& D) Unit. The C \& D Unit would be given a mission for moving forward. The branding would be part of a theme in building a new identity for the library unit. Recognizing the need to acquire, process, and provide access to collections in diverse formats, the $C$ \& D Unit would be flexible and creative in finding solutions to collection processing issues. The ability for staff members to recognize, analyze, and communicate solutions to daily workflow problems was an integral part of the new organization. In the previous technical service operations, daily workflow issues and problems associated with the fulfillment of patron requests, or the processing of materials such as questions about budgets or metadata quality would often be delayed due to the need to seek input from higher-level authorities, often a department head or librarian.

New staff positions such as collection specialist were established that had more authority and responsibility to find solutions for daily work problems. The new positions required analytical and technology skills as well. Technical services operations at the USF Library had been adopting more technology into daily workflows. In order to keep up with best practices and industry standards, investments were made in computer desktop applications and software suites. Growing collections in electronic 
resources involved the use of software tools for their management. Staff members in the C \& D Unit would need skills to use software tools such as Mircrosoft Excel and Access for data management tasks. Unit business transactions utilized digital business tools including PeopleSoft accounting software to process daily transactions. Other tools included MarcEdit and Aleph Integrated Library System software for bibliographic data editing. The new job classifications would help recruit individuals with the essential skills to succeed in the department. Besides recruiting new talent, a variety of training opportunities were offered to veteran staff members in the department. With cooperation from supervisors, staff members could create a development plan focusing on learning a particular skill. The information could be delivered either by being facilitated in class or self-paced through online education courses.

The C \& D Unit would also be a partner in new library programmatic initiatives by contributing resources and information as defined by library and university planning and directives. The new office spaces for technical services operations were optimized for technology with additional power and data lines. The floor design would have a mix of office and modular workspaces; a key planning component would be in facilitating interaction and communication among employees. The new office layout also reflected how computer technology had affected the contemporary environment of library technical services.

By the summer of 2018, the C \& D Unit's move to the sixth floor of the library was completed. The staff coalesced into teams and began working on a variety of issues related to electronic resource acquisitions and accessibility. The unit has been successfully managing over 900 database subscriptions, several DDA and EBA programs, and subscriptions allowing access to several thousand electronic journals. Already possessing a strong sense of mission, the new library unit has begun building a significant knowledge base that will no doubt position the Collections \& Discovery Unit for success as the academic environment at USF continues to evolve.

\section{References}

University of South Florida System. (2017-2018). USF system facts [Fact sheet]. Retrieved from University of South Florida website: https://www.usf.edu/ods/documents/system-facts/usf-system-facts-2017-18.pdf

Wenger, E. (1998). Communities of practice: Learning, meaning, and identity. New York, NY: Cambridge University Press. http://dx.doi.org/10.1017/CBO9780511803932 